\title{
Evaluation of Metal Contents in River Water Using a Simple Fractionation Method
}

\author{
Jun Kobayashi*,a and Ryoichi Kizu ${ }^{b}$ \\ ${ }^{a}$ Laboratory Sciences, School of Health Sciences, Faculty of Medicine, Kanazawa University, 5-11-80 Kodatsuno, Kanazawa $920-$ \\ 0942, Japan and ${ }^{b}$ Hygienic Chemistry, Faculty of Pharmaceutical Sciences, Kanazawa University, 13-1 Takara-machi, Kanazawa \\ 920-0934, Japan
}

(Received May 9, 2001; Accepted July 3, 2001)

In this study, we performed fractional partition and determination of metals in river water by filtering the sample through a membrane filter with pore size of $0.22 \mu \mathrm{m}$ immediately after sampling. We considered that the total amount of metal was contained in the nonfiltered sample, and fractional determination was performed separately using atomic absorption spectrometry of the metal in both the filtered and nonfiltered samples. The results showed a different pattern of aluminum distribution compared with other elements.

Key words — metal, river, water, sea, fractionation, filtration

\section{INTRODUCTION}

Environmental water, such as river water, well water, and sea water, is used for drinking water or for agricultural use. Many are apprehensive about the influence on humans since substances such as heavy metals contained in the water may be toxic in the body and the detailed mechanism of absorption is not yet understood. ${ }^{1-4)}$ In particular, the toxicity when absorbed in chemical form and the water solubility of heavy metals remain to be elucidated and concern has been growing about the contamination of water supplies with these and other metals. ${ }^{5,6)}$ In this study, simple fractionation partition and determination of the presence of several metals were performed using a membrane filter for environmental water, such as river water and sea water, and the results are discussed.

\section{MATERIALS AND METHODS}

\section{Sampling of River Water and Sea Water}

Samples were taken five times between October 2000 and February 2001. Ten sites in four Asano River valleys were sampled (the upper reaches of

*To whom correspondence should be addressed: Laboratory Sciences, School of Health Sciences, Faculty of Medicine, Kanazawa University, 5-11-80 Kodatsuno, Kanazawa 9200942, Japan. Tel.: +81-76-265-2609; Fax: +81-76-234-4369; Email: junkoba@mhs.mp.kanazawa-u.ac.jp the lower stream; upper region A1; middle region A2-3; and downstream region A4), where the river flows through Kanazawa city, Ishikawa, and into the Sea of Japan (the Uchinada seashore, A5), and in the four Kakehashi River valleys (the upper reaches of the lower stream; upper region $\mathrm{B} 1$; middle region B2-3; and downstream region B4) where the river flows through Komatsu city, Ishikawa and into the Sea of Japan (the Ataka seashore, B5). In addition, samples were taken on days without rain to avoid the possible influence of precipitation on water quality. Table 1 lists sampling sites and conditions. The sampling containers and preservation containers were predipped in detergent and diluted nitric acid and rinsed with Milli-Q water. At the time of sampling, water temperature (alcoholic thermometer) and air temperature (digital hygrothermometer, SIBATA TH-2 type) were also recorded.

Pretreatment of Samples — A portion of each sample was passed through a membrane filter with pore size of $0.22 \mu \mathrm{m}$ (Millipore OR type). Subsequently, concentrated nitric acid was added to reach a concentration of $0.1 \mathrm{M}$, and the samples were stored in polyethylene containers in a cool dark place. ${ }^{7)}$ Nonfiltered samples were processed similarly. Electrical conductivity (Horiba DS-14 type conductivity meter) and $\mathrm{pH}$ (Yokogawa PH82 type $\mathrm{pH}$ meter) were measured in the remaining sample portions.

Metal Analysis — Atomic absorption spectrometry was performed for metal analysis using ant Hitachi Z-8000-type atomic absorption spectropho- 
Table 1. Basic Conditions at Sampling Sites

\begin{tabular}{ccccc}
\hline \hline Sample & Air Temp. $\left({ }^{\circ} \mathrm{C}\right)$ & Water Temp. $\left({ }^{\circ} \mathrm{C}\right)$ & $\mathrm{pH}$ & Electronic Conductivit $(\mathrm{mS} / \mathrm{cm})$ \\
\hline A1 & $13.6 \pm 4.3$ & $10.8 \pm 4.7$ & $6.78 \pm 0.20$ & $1.050 \pm 0.156$ \\
A2 & $15.6 \pm 6.0$ & $12.2 \pm 5.0$ & $7.07 \pm 0.51$ & $1.404 \pm 0.213$ \\
A3 & $16.7 \pm 6.4$ & $12.8 \pm 5.0$ & $7.37 \pm 0.51$ & $1.386 \pm 0.268$ \\
A4 & $15.0 \pm 6.4$ & $12.0 \pm 6.4$ & $7.01 \pm 0.60$ & $4.062 \pm 1.305$ \\
A5 & $16.4 \pm 5.6$ & $16.4 \pm 4.6$ & $7.72 \pm 0.26$ & $>199.9$ \\
B1 & $15.4 \pm 6.2$ & $12.0 \pm 4.4$ & $7.25 \pm 0.43$ & $1.161 \pm 0.182$ \\
B2 & $16.0 \pm 6.9$ & $12.4 \pm 5.7$ & $7.00 \pm 0.20$ & $1.032 \pm 0.375$ \\
B3 & $17.2 \pm 6.0$ & $12.3 \pm 5.0$ & $6.97 \pm 0.12$ & $1.209 \pm 0.354$ \\
B4 & $15.4 \pm 5.5$ & $12.7 \pm 4.6$ & $6.94 \pm 0.18$ & $19.294 \pm 19.109$ \\
B5 & $15.5 \pm 5.0$ & $15.9 \pm 4.3$ & $7.66 \pm 0.21$ & $>199.9$ \\
\hline
\end{tabular}

Table 2. Metal Contents in River and Sea Water Samples

\begin{tabular}{|c|c|c|c|c|c|c|}
\hline \multirow[t]{2}{*}{ Sample } & \multirow[t]{2}{*}{ Filtration } & \multicolumn{5}{|c|}{ Metal (ppb) } \\
\hline & & $\mathrm{Al}$ & $\mathrm{Cr}$ & $\mathrm{Mn}$ & $\mathrm{Cd}$ & $\mathrm{Cu}$ \\
\hline \multirow{2}{*}{ A1 } & - & $113.59 \pm 126.31$ & $0.89 \pm 0.91$ & $5.11 \pm 3.52$ & $-^{a)}$ & $5.17^{b)}$ \\
\hline & + & $12.47 \pm 18.01$ & $0.22^{b)}$ & $2.87 \pm \quad 1.06$ & $\left.\_^{a}\right)$ & $ـ^{a)}$ \\
\hline \multirow{2}{*}{$\mathrm{A} 2$} & - & $58.56 \pm 41.08$ & $0.49 \pm 0.34$ & $12.61 \pm \quad 7.06$ & $\ldots$ a) & $1.10 \pm \quad 0.34$ \\
\hline & + & $7.54 \pm \quad 7.21$ & $0.24^{b)}$ & $11.47 \pm \quad 7.20$ & $\square^{a)}$ & $0.51^{b)}$ \\
\hline \multirow{2}{*}{ A3 } & - & $55.70 \pm 24.09$ & $1.09 \pm 1.43$ & $13.34 \pm \quad 7.63$ & $\_^{a)}$ & $11.09^{b)}$ \\
\hline & + & $7.57 \pm \quad 9.54$ & $0.26 \pm 0.04$ & $11.98 \pm \quad 7.76$ & $-^{a)}$ & $\_^{a)}$ \\
\hline \multirow{2}{*}{ A4 } & - & $262.59 \pm 56.62$ & $0.36 \pm 0.15$ & $328.60 \pm 251.59$ & $0.060^{b)}$ & $4.48 \pm \quad 6.31$ \\
\hline & + & $5.88 \pm \quad 0.82$ & $\_^{a)}$ & $290.10 \pm 255.12$ & $0.053^{b)}$ & $1.61 \pm \quad 1.42$ \\
\hline \multirow{2}{*}{ A5 } & - & $25.88 \pm 11.00$ & $0.57 \pm 0.30$ & $19.00 \pm \quad 5.26$ & $0.616 \pm 0.232$ & $298.99 \pm 290.03$ \\
\hline & + & $4.49 \pm \quad 5.14$ & $0.52 \pm 0.26$ & $13.73 \pm \quad 4.03$ & $0.501 \pm 0.286$ & $91.15 \pm 55.05$ \\
\hline \multirow{2}{*}{ B1 } & - & $35.73 \pm 17.46$ & $0.91^{b)}$ & $26.25 \pm 12.18$ & $0.791 \pm 0.236$ & $17.62 \pm 8.98$ \\
\hline & + & $4.93 \pm \quad 3.22$ & $\ldots^{a)}$ & $25.75 \pm 12.09$ & $0.439 \pm 0.095$ & $12.83 \pm \quad 7.03$ \\
\hline \multirow{2}{*}{ B2 } & - & $40.03 \pm 7.96$ & $ـ^{a)}$ & $23.78 \pm 7.57$ & $0.336 \pm 0.076$ & $10.96 \pm 10.74$ \\
\hline & + & $5.14 \pm \quad 1.43$ & $\_^{a)}$ & $22.56 \pm \quad 8.42$ & $0.187 \pm 0.090$ & $5.28 \pm \quad 2.97$ \\
\hline \multirow{2}{*}{ B3 } & - & $69.98 \pm 41.32$ & $1.35^{b)}$ & $47.57 \pm 14.23$ & $0.281 \pm 0.139$ & $6.57 \pm$ \\
\hline & + & $4.03 \pm \quad 1.26$ & $\_^{a)}$ & $45.56 \pm 14.10$ & $0.217 \pm 0.106$ & $4.83 \pm \quad 2.44$ \\
\hline \multirow{2}{*}{ B4 } & - & $72.78 \pm 22.74$ & $0.28 \pm 0.06$ & $65.32 \pm 13.86$ & $0.153 \pm 0.085$ & $7.67 \pm \quad 6.45$ \\
\hline & + & $2.25 \pm \quad 0.95$ & $\ldots^{a)}$ & $62.19 \pm 15.57$ & $0.124 \pm 0.079$ & $2.49 \pm \quad 1.37$ \\
\hline \multirow{2}{*}{ B5 } & - & $22.15 \pm 10.94$ & $0.56 \pm 0.40$ & $24.47 \pm 10.00$ & $0.701 \pm 0.274$ & $78.78 \pm 25.54$ \\
\hline & + & $\_^{a)}$ & $0.64 \pm 0.35$ & $19.45 \pm 11.12$ & $0.616 \pm 0.266$ & $63.11 \pm 29.28$ \\
\hline
\end{tabular}

Data shown as mean $(n \leq 5) \pm$ S.D. $a)$ not calculated since the value was less than the determination limit. $b) n=1$.

tometer. Five elements were measured: aluminum (Al); cadmium $(\mathrm{Cd})$; chromium $(\mathrm{Cr})$; copper $(\mathrm{Cu})$; and manganese (Mn). To measure the metal in the samples from the viewpoint of contamination from the surrounding environment and the concentration of the five metals in a sample, the measurement was carried out in the order $\mathrm{Al} \rightarrow \mathrm{Mn} \rightarrow \mathrm{Cd} \rightarrow \mathrm{Cu} \rightarrow$ $\mathrm{Cr}$. In addition, sea water samples or samples suspected to contain sea water, and samples deviating from the maximum range of the calibration curve were measured again after dilution with $0.1 \mathrm{M} \mathrm{ni-}$ tric acid. 
Table 3. Proportions of Filtered Metals in River and Sea Water Samples

\begin{tabular}{|c|c|c|c|c|c|}
\hline \multirow[t]{2}{*}{ Sample } & \multicolumn{5}{|c|}{ Proportion of metals filtered fractions $(\%)^{a)}$} \\
\hline & $\mathrm{Al}$ & $\mathrm{Cr}$ & $\mathrm{Mn}$ & $\mathrm{Cd}$ & $\mathrm{Cu}$ \\
\hline A1 & $4.85 \pm 4.57$ & $14.38^{b)}$ & $64.90 \pm 21.47$ & $-^{c)}$ & $-^{c)}$ \\
\hline $\mathrm{A} 2$ & $12.40 \pm 11.73$ & $96.00^{b)}$ & $86.03 \pm 13.52$ & $-c)$ & $-c)$ \\
\hline A3 & $10.48 \pm 10.23$ & $97.93 \pm 13.40$ & $83.19 \pm 16.83$ & $-c)$ & $-c)$ \\
\hline A4 & $2.44 \pm 0.84$ & $-\epsilon^{c)}$ & $82.50 \pm 19.08$ & $88.33^{b)}$ & $40.62 \pm 30.95$ \\
\hline A5 & $4.34^{b)}$ & $77.46 \pm 2.03$ & $72.63 \pm 12.44$ & $77.30 \pm 17.36$ & $44.47^{b)}$ \\
\hline B1 & $14.34 \pm 5.93$ & $-c)$ & $97.42 \pm 3.10$ & $61.47 \pm 27.18$ & $73.91 \pm 11.65$ \\
\hline B2 & $12.47 \pm 3.57$ & $-c)$ & $93.36 \pm 6.21$ & $61.29 \pm 37.34$ & $59.10 \pm 19.88$ \\
\hline B3 & $8.24 \pm 4.65$ & $-^{c)}$ & $95.55 \pm 2.65$ & $79.68 \pm 21.79$ & $72.68 \pm 10.08$ \\
\hline B4 & $2.87 \pm 1.54$ & $-^{c)}$ & $94.43 \pm 5.26$ & $80.29 \pm 3.88$ & $39.80 \pm 18.40$ \\
\hline B5 & $\_^{c)}$ & $87.33 \pm 0.94$ & $75.91 \pm 17.75$ & $87.43 \pm 8.28$ & $78.21 \pm 15.21$ \\
\hline Mean & 8.1 & 74.6 & 84.6 & 76.5 & 58.4 \\
\hline S.D. & 4.6 & 34.6 & 10.9 & 11.1 & 16.8 \\
\hline
\end{tabular}

a) Data shown as mean $(n \leq 5) \pm$ S.D. $b) n=1$. $c$ ) Not calculated since the value was less than the determination limit.

\section{RESULTS AND DISCUSSION}

The results of determination of metal contents are shown in Table 2. Measurements of lead and nickel were below the level of sensitivity in all samples ( $\mathrm{Pb}, 2 \mathrm{ppb}$; nickel, $1 \mathrm{ppb})$. The concentration of each element differed by sampling site. Concentrations in the filtered and nonfiltered samples were as follows: Al, 22.2-262.6 ppb (nonfiltered sample) $/<0.5-12.5 \mathrm{ppb}$ (filtered sample); $\mathrm{Cr},<0.2-$ $1.1 \mathrm{ppb} /<0.2-0.64 \mathrm{ppb} ; \mathrm{Mn}, 5.1-328.6 \mathrm{ppb} / 2.9-$ $290.1 \mathrm{ppb} ; \mathrm{Cd},<0.05-0.79 \mathrm{ppb} /<0.05-0.62 \mathrm{ppb}$; and $\mathrm{Cu}, 1.1-299.0 \mathrm{ppb} /<0.5-91.2 \mathrm{ppb}$. The variations were considered to reflect elution from soil, artificial contamination, and changes in the form of the metals over time. In particular, it was hypothesized that contamination would be more marked in the downstream sites (A4 and B4) of the rivers because of the formation of tidal flats and water stagnation. This hypothesis correlated with the color and quantity of residue on the filters at the time of filtration. Most metals were detected in both filtered and nonfiltered samples, and the high-polymer or insoluble fractions were larger than soluble (low molecular weight) fractions that can pass through $0.22 \mu \mathrm{m}$ pore size filter. In the comparison of elements, aluminum showed a pattern different from other elements: the partition of the water-soluble fractions (A5 and B5) of sea water was very low (Table 3). Since conditions (temperature, $\mathrm{pH}$, time until it enters water from soil, etc.) were consistent in sea water, it was thought that high polymerization (formation of huge particles) was occuring. ${ }^{8}$ )
Moreover, the soluble fraction was $12 \%$ or less, which supports the occurrence of high polymerization. The percentagerate of aluminum in the filtered samples corresponds with the results in our previous reports. ${ }^{5)}$

Thus, although the fractionation and determination of elements of all molecular weights and of soluble/insoluble fractions were not performed, it was possible to collect a large amount of useful data simply and quickly using the current method compared with the column method or dialyzing method. ${ }^{9)}$ Although not used in this investigation, we believe that if an acid-proof filter such as polytetrafluoroethylene (PTFE) is used then filtration after acid processing would also be possible. In addition, even if atomic absorption spectrometry is used alone, variable fractionation analysis such as of the acidsoluble/insoluble fractions is expected to become possible.

Acknowledgements This research was made possible by an Area-Studies Grant-in-Aid (2000) from Kanazawa city. We would also like to thank Professor Kazuichi Hayakawa, Department of Pharmacy, Kanazawa University, for his encouragement during this research.

\section{REFERENCES}

1) Wada, O. (1985) Kinzoku to hito - Ecotoxicology to Rinsho - (Metal elements and human beings; with emphasis on clinical ecotoxicology), Asakura 
Shoten, Tokyo, p. 233. (In Japanese)

2) Sharpe, W. E. and De Walle, D. R. (1985) Potential health implications for acid precipitation, corrosion, and metals contamination of drinking water. Environ. Health Perspect., 63, 71-78.

3) Gerhardsson, L., Oskarsson, A. and Skerfving, S. (1994) Acid precipitation - effects on trace elements and human health - Sci. Total Environ., 153, 237-245.

4) Pina, R. G. and Cervantes, C. (1996) Microbial interactions with aluminium. Biometals, 9, 311-316.

5) Kobayashi, J. and Miyazaki, M. (1995) Determination of aluminum in tap water and environmental waters by flow injection analysis. Hokuriku J. Public Health, 21, 51-55.

6) Harris, W. R., Berthon, G., Day, J. P., Exley, C., Flaten, T. P., Forbes, W. F., Kiss, T., Orvig, C. and
Zatta, P. F. (1996) Speciation of aluminum in biological systems. J. Toxicol. Environ. Health, 48, 543568.

7) Hukuzaki, N., Hara, H. and Ayers, G. P. (1999) Comparison of the rain sample preservation method. $J$. Jap. Soc. Atmospheric Environ., 34, 35-41.

8) Rocha, J. C., de Sene, J. J., dos Santos, A., Toscano, I. A. and Zara, L. F. (2000) Aquatic humus from an unpolluted Brazilian dark-brown stream: general characterization and size fractionation of bound heavy metals. J. Environ. Monit., 2, 39-44.

9) Wickstrom, T., Clarke, N., Derome, K., Derome, J. and Rogeberg, E. (2000) Comparison study of five analytical methods for the fractionation and subsequent determination of aluminium in natural water samples. J. Environ. Monit., 2, 171-181. 